\title{
Work Practices in Small and Marginal Farm Holdings: An
}

\section{Ergonomics Analysis}

\section{Mondal T* and Nag PK \\ IRDM Faculty Centre, Ramakrishna Mission Vivekananda Educational and Research Institute, India}

*Corresponding author: Tandra Mondal, IRDM Faculty Centre, Ramakrishna Mission

\section{Research Article \\ Volume 2 Issue 5}

Received Date: August 19, 2018

Published Date: September 29, 2018

DOI: $10.23880 /$ eoij- 16000180 Vivekananda Educational and Research Institute, Narendrapur, Kolkata-700103, India, Email: tandraghum@gmail.com

\section{Abstract}

This present contribution elucidates the extent of use of tools and machinery, human energy spent, man hours involved and work severity among the rice farmers of the state of Wes Bengal, India. The study covered a single paddy growing season, i.e., monsoon spanning from July to December and objective data were gathered from 400 farmers. The level of mechanization in the studied area, however, remains scattered due to the compulsiveness to the situation dominated by the economic layout of farm holdings, land size, and large-scale deprivation of access to the technology suitable to small holdings. Analysis revealed paddy cultivation in this region is dependent on manual labour, about 100-130 man-days per ha is required in a single paddy growing season. Except for land preparation, most of the tasks are dependent on manual labour and manually operated tools and devices. Sowing, harvesting, and weeding are found to be the most labour intensive task. All the tasks related to rice cropping activities are grouped into five distinct categories to indicate the level of work severity involved in each task. The study provides an insight by comparing total human energy requirement to different farm activities and manpower involvement per unit land. Therefore, the need for design and development of efficient small machinery and manually operated devices exist to reduce drudgery and match requirements of the farm workers in small holdings.

Keywords: Small and Marginal Holding; Drudgery Proneness; Man-Hours; Scale Specific Technology

\section{Introduction}

Worldwide, the farming sector is dominated by small and marginal holdings (SMH) in the range of $<1$ to 2 ha, i.e., nearly $84 \%$ of the total number of farms [1]. Labour intensiveness, family farming, dependence on age-old farming tools and practices make this farming sector more economically vulnerable. The output and efficiency of the SMH are insignificant in comparison to mechanized farms with large farm holdings, and therefore, the policymakers often view that farm mechanization is the avenue for the emancipation of their backwardness [2,3]. Farming sector in India employs about 263 million workforces and emerges primarily as a distinct face of SMH category [4]. These farms have meager resources and are maintained by family labors to grow staple food grains 


\section{Ergonomics International Journal}

[5-7]. In India, this sector acknowledges a gradual transformation from traditional to modern methods of farm practices, yet the farm mechanization lacks uniformity across region and crops due to the compulsiveness of poor economic layout of farm holdings, and large- scale deprivation of technology suitable to $\mathrm{SMH}$ [8-10]. The tractor density of northern India (Punjab, Haryana, Uttar Pradesh) is higher than in other states [11]. The present scenario of SMH might continue to prevail for decades to come, and therefore, the imperatives are to continually search avenues to alleviate their perceptible risks of uncertainty, potential drudgery proneness and improve in their farm productivity [12]. This contribution is a macro ergonomics analysis of rice cropping in $\mathrm{SMH}$, elucidating the extent of use of tools and machinery, the human energy spent, man hours involved and work severity related to farmingactivities.

\section{Methods}

The study was carried out in the farming districts of the state of West Bengal of eastern India, where paddy, potato, vegetables, and jute (totaling about 8 million ha) are the primary crops regarding land utilization and total production [13]. West Bengal produces nearly 15 million tons of rice, contributing about $15 \%$ of India's total paddy production [4]. Three districts of West Bengal, i.e., Burdwan, Hooghly and South 24 Parganas were selected. Burdwan and Hooghly are the front-runners in producing paddy. The mechanization in the rice cropping is generally low [14]. The state of West Bengal is dominated by SMH (i.e., $96 \%$ of the total farm families) with an average land holding of 0.77 ha, and cropping intensity of $182 \%$ [13]. A single paddy growing season, i.e., monsoon spanning from July to December was covered in the study, and objective data on the cropping activities, including crops time, span, and frequency of each activity starting from land preparation to harvesting, labour requirement, types of machinery and hand tools used were gathered from 400 farmers. From the record of the number of days involved in each cropping activity per ha land, the total man-days required in the cropping and the extent of human energy expenditure of the activities was estimated, taking into average 7 working hours per day. Hence, the energy requirement per ha of land in paddy cultivation was obtained from the total number of manhours required, multiplied by the energy value linked to the task. Besides, a questionnaire survey was introduced among the farmworkers to obtain information related to perceived drudgery, accident risks, and other related factors.

\section{Results}

The present analysis in SMH indicated a diversity of farming activities, use of hand tools, manually operated devices, and machinery in rice cropping from seedbed preparation to harvesting. The use of heavy machinery (tractor and power tiller, hired on a rental basis) was primarily limited to land preparation. In other activities, the traditional hand tools and smaller manually operated devices were used. Farmworkers in SMH used manual methods in sowing, transplanting, weeding, and also in cases of threshing by manual pounding. Sowing, weeding, and harvesting were some of the most labour intensive tasks. Pesticide application was generally performed using knapsack sprayer. The sickle as a harvesting tool was common across the farmworkers. Use of transplanter, seeder or harvester was not very common among SMH. Figure 1 illustrates selected farm activities in paddy cultivation.
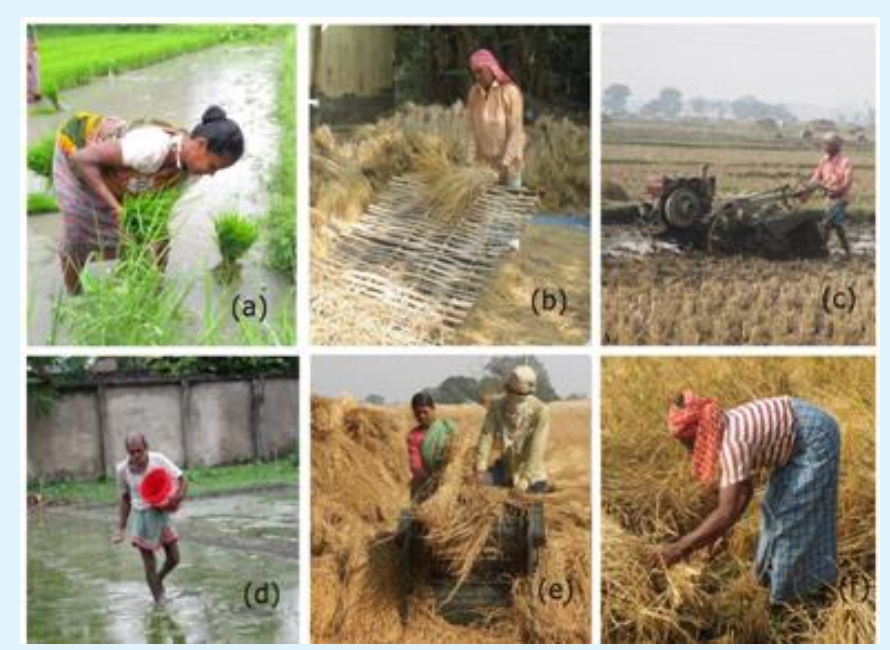

Figure 1: Farming practices (a) manual transplanting; (b) threshing paddy by beating; (c) land preparation with power tiller; (d) fertilizer broadcasting; (e) pedal thresher operation; (f) harvesting paddy with sickle.

The activities, tools, and machinery used, and the manhours required for different tasks are given in Table 1. Activities, such as sowing and transplanting by hand, weeding by the spade, harvesting of the crop by sickle, the manual carrying of crop materials on the yoke, and threshing of grains from paddy pinnacle were the labour intensive tasks, and a substantial number of days was spent per ha of land. Threshing of grain by pedal thresher was more effective than threshing by manual pounding. The work severity appeared to change with the tools or 


\section{Ergonomics International Journal}

machinery used. Use of tractor for land preparation was found to be a less human energy demanding, in comparison to tillage by power tiller and other farm activities. Nag, et al. (1980) [15] categorized work severity into five classes, i.e. light, moderate, moderately heavy, heavy and unduly heavy. Using this classification work severity of rice cropping activities is grouped into distinct categories, as shown in Figure 2.

\begin{tabular}{|c|c|}
\hline $\begin{array}{c}\text { Hand Tool Technology/Mechanical } \\
\text { Power Technology }\end{array}$ & $\begin{array}{c}\text { Man Hours } \\
\text { (ha) }\end{array}$ \\
\hline Tillage by tractor & 5 \\
\hline Tillage by power tiller & 10 \\
\hline Sowing and transplanting by hand & 192 \\
\hline
\end{tabular}

\begin{tabular}{|c|c|}
\hline Weeding by spade & 142 \\
\hline Fertilizer broadcasting by hand & 10 \\
\hline Pesticide application by knapsack sprayer & 7 \\
\hline Harvesting by sickle & 181 \\
\hline Threshing by pedal thresher & 188 \\
\hline Threshing by pounding & 248 \\
\hline Carrying crop materials on the yoke & 259 \\
\hline Transporting crop material by a tractor & 10 \\
\hline
\end{tabular}

Table 1: Man hours' distribution in different rice farming activities.

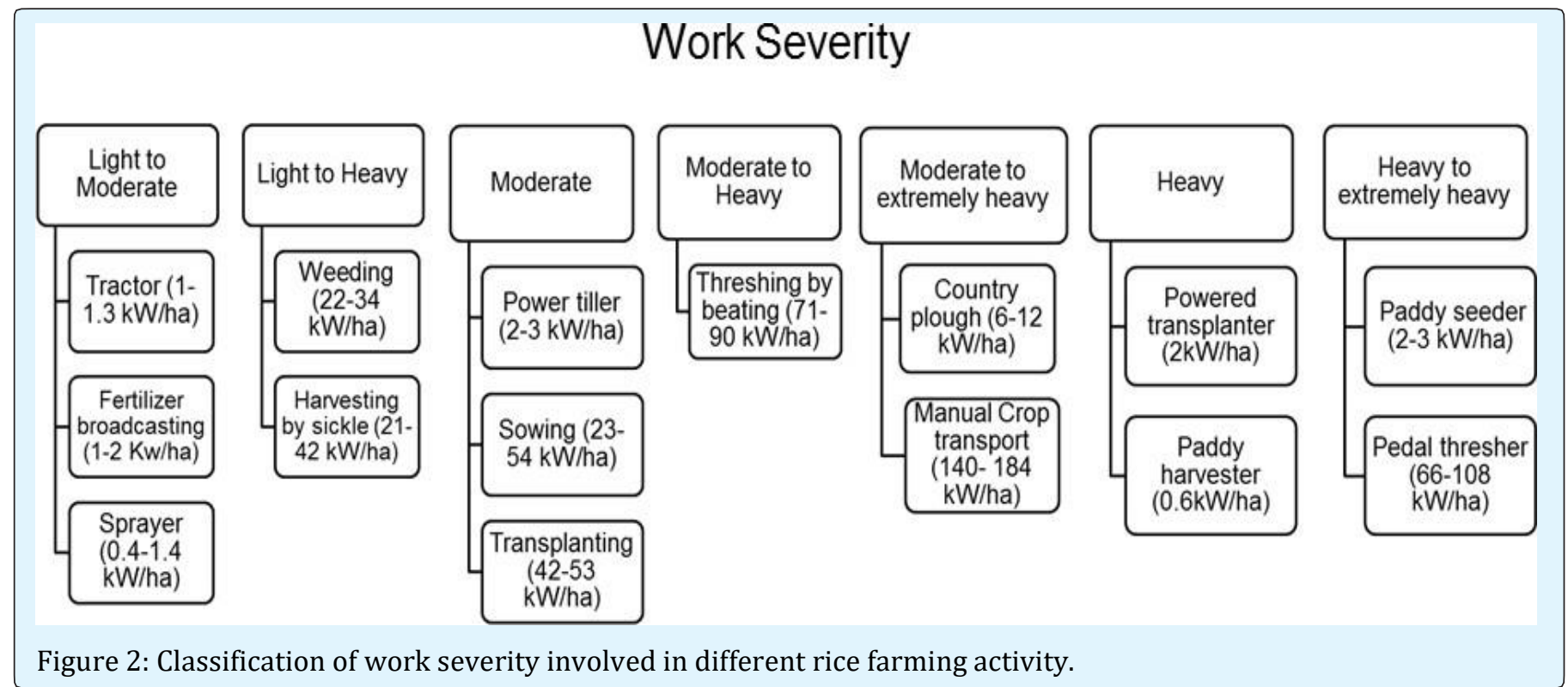

\section{Discussion}

The SMH in India collectively represent $\sim 85 \%$ of the total number of operational holding and $45 \%$ of the total operational area $[4,16]$. The study evidently indicated that paddy cultivation is a labour intensive task, requiring about 100-130 man-days per ha. The use of machinery was primarily limited to land preparation, using a tractor or power tiller. In most other activities, the farmworkers depended on traditional hand tools and smaller manually operated devices $[13,14,17]$. Whereas the use of the tractor for land preparation was found to be a less human energy demanding, in some cases, the work severity increased with the introduction of mechanical tool or devices. For example, energy demands and work severity in machinery operation, like powered transplanter, harvester, and seeder were categorized as heavy to extremely heavy, indicating that challenges remain for improvisation of the devices to mitigate human drudgery. Apparently less energy demanding tasks, such as transplanting, harvesting, and sowing required nearly half of the total man hour involved in rice farming. Therefore, the total energy expenditure even for relatively less severe tasks was high per ha of land. There was also a comparable situation in case of the use of pedal thresher, in which the drudgery level was higher as compared to threshing by pounding. Since the man-hours required completing a task was less in a pedal thresher, the cumulative demand was also less in comparison to manual threshing. Work severity is relatively lower for 


\section{Ergonomics International Journal}

land preparation activities using the tractor, broadcasting fertilizer and spraying pesticide with knapsack sprayer as these tasks fall in light to moderate category.

The SMH with limited capital resources is barely capable of introducing machinery $[18,19]$. Despite the introduction of several farm machinery and increase in total farm power availability, the overall coverage of machinery is only about $1 / 4^{\text {th }}$ of the total farms in India, and proportion is much less in case SMH. Large machinery often remains under-utilized due to lack of skill and training [11,20,21]. Presence of bunds in the fragmented land pockets restricts the reach of the tractor to the furthest corners. In remote places, use of the machines becomes a burden to farmers due to the absence of maintenance facility of implements. Undoubtedly, mechanization improves the timeliness and hence increases the productivity and reduces overall human drudgery [22]. However, occasional peak energy demands with a certain category of machinery making them risk and accident prone due to physical fatigue of the farm operators [23]. The SHM studied in the selected districts is representative scenario of the small and marginal farmers in terms of their work severity and efficiency. The state of farm mechanization analyzed through the growth of power-operated farm machinery over traditional human and animal power operated tools and devices have been emphasized [24,25]. The conventional method of estimating the state of mechanization has only a marginal consideration to the animate power sources since human energy output cannot be equated to electrical energy. In labor-intensive farming, quantification of energy utilization should primarily be linked to drudgery proneness and human energy expenditure. There are obvious necessities to examine the socio-economic and cultural motivation of the SMH and avenues for work simplification [19]. There is an apparent demand of need-based and scale specific technology to match the requirements in the prevailing situations, with due account of the economic viability of SMH [12]. That is, scope remains in design and development of efficient small machinery and manually operated devices to match requirements of the farm workers in small holdings and reduce drudgery and accident proneness.

\section{Conclusion}

The average land holding size of Indian states fall at a dismal level of 1.16 ha and the small and marginal farmers represent nearly $80 \%$ of the total number of farms. Sample representative investigation indicates that the $\mathrm{SMH}$ face excruciating challenges of survival and existence due to lack of resources, financial layout and access to appropriate technology. The study evolves a relationship of the total human energy requirement to different farm activities and manpower involvement per unit land. Because significant farm power utilization comes from animate sources including human and draught animals, the farm productivity relationship to the state of mechanization in the SMH in terms of mechanical energy used and human labour involvement to may be ascertained.

\section{References}

1. Lowder SK, Skoet J, Raney T (2016) The number, size, and distribution of farms, smallholder farms, and family farms worldwide. World Development 87: 1629.

2. Pimentel D, Doughty R, Carothers C, Lamberson S, Bora N, et al. (2002) Energy inputs in crop production: comparison of developed and developing countries. In: Lal R., Hansen D, Uphoff N, Slack S (Eds.), Food Security and Environmental Quality in the Developing World, CRC Press, Boca Raton, pp: 129-151.

3. Schmitz A, Moss CB (2016) Mechanized agriculture: Machine adoption, farm size, and labor displacement. The Journal of Agro biotechnology Management and Economics 18(3): 278-296.

4. The government of India (2017) Agricultural statistics at a glance 2016. Directorate of Economics and Statistics, Department of Agriculture and Cooperation, Ministry of Agriculture. New Delhi, India.

5. World Bank (2003) Reaching the rural poor: A renewed strategy for rural development. Washington DC.

6. Dixon J, Taniguchi K, Wattenbach H (2003) Approaches to assessing the impact of globalization on African smallholders: Household and village economy modelling. Proceedings of a working session on Globalization and the African Smallholder Study. Food and Agriculture Organization, Rome.

7. Hazell PB, Poulton C, Wiggins S, Dorward A (2007) The Future of small farms for poverty reduction and growth. International Food Policy Research Institute (IFPRI), Washington DC. 


\section{Ergonomics International Journal}

8. Singh G (2006) Estimation of a mechanisation index and its impact on production and economic factors-A case study in India. Biosystems Engineering 93(1): 99-106.

9. Akdemir B (2013) Agricultural mechanization in Turkey. IERI Procedia 5: 41-44.

10. Van den Berg MM, Hengsdijk H, Wolf J, Van Ittersum MK, Guanghuo W, et al. (2007) The impact of increasing farm size and mechanization on rural income and rice production in Zhejiang province, China. Agricultural Systems 94(3): 841-850.

11. Singh J (2005) Scope, progress and constraints of farm mechanization in India. In: Tyagi $\mathrm{K}$, Bathla $\mathrm{H}$, Sharma S (Eds.), Status of Farm Mechanization in India. Indian Agricultural Statistics Research Institute, New Delhi.

12. Mehta CR, Chandel NS, Senthilkumar T (2014) Status, challenges and strategies for farm mechanization in India. Agricultural Mechanization in Asia Africa and Latin America 45(4): 43-50.

13. Tewari VK, Kumar AA, Kumar SP, Nare B (2012) Farm mechanization status of West Bengal in India. Basic Research Journal of Agricultural Science and Review 1(6): 139-146.

14. Paman U, Inaba S, Uchida S (2014) The mechanization of small-scale rice farming: Labor requirements and costs. Engineering in Agriculture, Environment and Food 7(3): 122-126.

15. Nag PK, Sebastian NC, Mavlankar MG (1980) Occupational workload of Indian agricultural workers. Ergonomics 23(2): 91-102.

16. Ghatak M, Roy S (2007) Land reform and agricultural productivity in India: a review of the evidence. Oxford Review of Economic Policy 23(2): 251-269.

17. Yadav SN, Chandra R, Khura TK, Chauhan NS (2013) Energy input- output analysis and mechanization status for cultivation of rice and maize crops in Sikkim. Agricultural Engineering International: CIGR Journal 15(3): 108-116.
18. Thapa G (2009) Smallholder farming in transforming economies of Asia and the Pacific challenges and opportunities. In: Discussion Paper Prepared for the Side Event Organized during the Thirty-third Session of IFAD's Governing Council, International Fund for Agricultural Development (IFAD), Rome.

19. Mottaleb KA, Krupnik TJ, Erenstein O (2016) Factors associated with small-scale agricultural machinery adoption in Bangladesh: Census findings. Journal of rural studies 46: 155-168.

20. Kawasaki K (2010) The costs and benefits of land fragmentation of rice farms in Japan. Australian Journal of Agricultural and Resource Economics 54(4): 509-526.

21. Foster A, Rosenzweig M (2010) Barriers to farm profitability in India: mechanization, scale and credit markets. In: Paper Presented at the Conference Agriculture for Development- Revisited, University of California, Berkeley, CA.

22. Muazu A, Yahya A, Ishak WIW, Khairunniza-Bejo S (2014) Machinery Utilization and Production Cost of Wetland, Direct Seeding Paddy Cultivation in Malaysia. Agriculture and Agricultural Science Procedia 2: 361-369.

23. Nag PK, Nag A (2004) Drudgery, accidents and injuries in Indian agriculture. Industrial Health 42(2): 149-162.

24. Hormozi MA, Asoodar MA, Abdeshahi A (2012) Impact of mechanization on technical efficiency: A case study of rice farmers in Iran. Procedia Economics and Finance 1: 176-185.

25. Fortune C, Tawanda D (2013) An Assessment of Agricultural Mechanization Index and Evaluation of Agricultural Productivity of some Fast Track Resettlement Farms in Bindura District of Mashonaland Central Province: Zimbabwe. International Journal of Social Science \& Interdisciplinary Research 2(7): 62-82. 